\title{
Autopercepção de competências transversais de trabalho em universitários: construção de um instrumento
}

\author{
Bárbara Maria Barbosa Silva \\ Faculdade Integrada de Santa Maria \\ Marco Antônio Pereira Teixeira \\ Universidade Federal do Rio Grande do Sul
}

\begin{abstract}
Resumo
O sucesso e a permanência no mercado de trabalho não estão ligados somente às competências técnicas e específicas de cada profissão. Competências transversais, ou seja, que podem ser transferidas de um contexto a outro de trabalho, são cada vez mais importantes. O objetivo principal desta pesquisa foi a construção de um instrumento para avaliar a autopercepção de competências transversais de trabalho em universitários. A amostra foi composta por 777 universitários de 34 cursos diferentes com idades entre 18 e 33 anos. Resultados de análises de componentes principais indicaram sete dimensões no instrumento: resolução de problemas e criatividade, organização e responsabilidade, relacionamento interpessoal, trabalho em equipe, comunicação escrita, comunicação oral e raciocínio numérico. Os índices de fidedignidade obtidos foram todos satisfatórios (entre 0,74 e 0,91 ). Estes resultados sugerem que o instrumento proposto apresenta boas qualidades psicométricas, embora novos estudos de validade sejam necessários.
\end{abstract}

Palavras-chave: competências transversais; avaliação; ensino superior; formação profissional.

\begin{abstract}
Self-perception of work transferable skills among university students: construction of an instrument. Success and permanence in the labor market do not depend only on individuals' possession of specific and technical skills of her or his occupation. Transferable skills, which can be transferred from one context of work to another, are increasingly important. The main objective of this research was the construction of an instrument to assess self-perceptions of work transferable skills among university students. The sample was composed of 777 students from 34 different courses, aged between 18 and 33 years. Principal components analysis results revealed seven dimensions in the instrument: problem-solving and creativity, organization and responsibility, interpersonal relationship, teamwork, written communication, oral communication and numeric reasoning. All reliability indexes obtained were satisfactory (between 0.74 and 0.91 ). These results suggest that the proposed instrument shows good psychometric properties, although further validity studies are needed.
\end{abstract}

Keywords: transferable skills; assessment; higher education; professional education.

$\mathrm{O}$ conceito de competência tem ganhado relevância nos campos da educação e do trabalho nos últimos anos. Para Le Boterf (2003), competência pode ser entendida, em sentido amplo, como um saber em ação. Competência envolve, portanto, uma junção de conhecimentos (saber o quê fazer), habilidades (saber como fazer, ter a capacidade de) e atitudes (estar motivado para fazer, interagindo com o meio de modo apropriado a fim de atingir o objetivo). A importância desse conceito para as áreas da educação e do trabalho está no fato de que o que se espera de um bom profissional não é apenas conhecimento teórico ou técnico sobre um assunto, mas sim que este demonstre competência, ou seja, que saiba aplicar os conhecimentos em situações da vida real, sabendo ajustar-se a diferentes contextos (Le Boterf, 2003; Moreno, 2006).
Nessa lógica, a educação profissional deveria promover o desenvolvimento de competências, e não apenas transmitir conhecimentos como costuma ser o caso. As competências técnicas, contudo, não são suficientes para um bom desempenho profissional. A sua efetiva implementação se apoia na maioria das vezes em outras competências, mais genéricas, relacionadas ao mundo do trabalho (Moreno, 2006). Estas outras competências são usualmente denominadas de competências transversais de trabalho, ou ainda, segundo alguns autores, de competênciaschave, genéricas, essenciais ou transferíveis (Cabral-Cardoso, Estêvão, \& Silva, 2006).

As competências transversais de trabalho podem ser entendidas como atitudes, capacidades e habilidades do indivíduo que contribuem para uma atuação eficaz em diferentes situações 
de trabalho, sendo transferíveis de um contexto para outro ao longo da vida (Moreno, 2006). Alguns exemplos são a capacidade de trabalho em equipe, a responsabilidade e a comunicação. Elas se distinguem, portanto, das competências técnicas que dizem respeito ao desempenho em tarefas específicas de cada profissão. As competências transversais, assim, são elementos que favorecem o bom desempenho no mundo do trabalho, uma vez que ajudam os sujeitos a lidarem melhor com diferentes tipos de situações laborais e facilitam a aplicação das suas competências técnicas (Moreno, 2005).

O desenvolvimento de competências, tanto técnicas quanto transversais, está bastante relacionado aos processos de formação dos profissionais. Nesse sentido, instituições de ensino superior, especialmente na Europa, têm buscado introduzir mudanças curriculares e pedagógicas (através de atividades curriculares e extracurriculares) que têm por objetivo promover o desenvolvimento de habilidades e atitudes que facilitem a transição para o mercado de trabalho e possibilitem o progresso na carreira (Alpay \& Walsh, 2008; Cox \& King, 2006; Drummond, Nixon, \& Wiltshire, 1998; Moreno, 2005; Nabi \& Bagley, 1999). Nessa perspectiva, amplia-se o papel atribuído à formação universitária. Para além de capacitar tecnicamente os indivíduos para atuarem em áreas específicas, o ensino superior também deveria preparar o indivíduo para saber transitar no mercado de trabalho, atual e futuro, no sentido da otimização de suas capacidades (Moreno, 2005; Zabalta, 2004).

Pesquisas com universitários e recém-graduados sugerem que os estudantes percebem a importância das competências transversais para a sua inserção no mercado de trabalho e progresso profissional (Burke, Jones, \& Doherty, 2005; CabralCardoso et al., 2006; Nabi \& Bagley, 1999; Whittle \& Eaton, 2001; Zekeri, 2004). De fato, os empregadores valorizam em seus empregados muitas habilidades que não estão presentes formalmente nos currículos de formação superior (Campos et al., 2008; Frame \& Canter, 2001). Pesquisas como essas sugerem que a atenção na formação deve estar voltada para a aprendizagem de resolução de problemas profissionais da vida real, nos quais as competências transversais são mais nitidamente necessárias, e não apenas a problemas teóricos ou acadêmicos (Zekeri, 2004).

No entanto, nem sempre os estudantes percebem que o ensino superior promove o desenvolvimento de competências. Por exemplo, Lucas, Cox, Croudace e Milford (2004) verificaram que estudantes universitários tinham noções pouco claras sobre o que eram competências transversais e como elas eram desenvolvidas no curso. Os alunos tendiam a associar as competências a atributos pessoais, não as percebendo como algo passível de ser aprendido e desenvolvido. Embora reconhecessem que algumas tarefas acadêmicas possibilitassem uma oportunidade para o uso das competências (por exemplo, em trabalhos de grupo), o desenvolvimento dessas habilidades foi percebido como algo decorrente da maturação e que se daria automaticamente, dependendo mais de características pessoais do que da própria experiência de formação. Para os autores, estes resultados indicam a importância de se trabalhar o conceito de competências junto aos alunos, construindo um vocabulário a partir do qual as experiências de aprendizagem possam ser discutidas e avaliadas.
Dado esse contexto, percebe-se que é importante avaliar como os estudantes do ensino superior percebem estas competências e o seu desenvolvimento. A avaliação das competências transversais pode ter implicações tanto no âmbito pessoal quanto no institucional. No nível pessoal, tal avaliação pode estimular o autoconhecimento e a busca por desenvolvimento pessoal, permitindo a identificação de competências já bem desenvolvidas e outras que eventualmente necessitem ser aprimoradas, visando a formação de um profissional mais capaz de adaptar-se a diferentes contextos de trabalho e com maior potencial de se inserir e manter no mercado. No nível institucional, a avaliação pode servir para diagnosticar competências que, na percepção dos alunos, necessitam ser mais bem desenvolvidas, o que pode ser viabilizado através da oferta de intervenções específicas voltadas a esse fim ou então através de uma reorganização curricular e pedagógica que estabeleça como objetivos de aprendizagem o desenvolvimento dessas competências. Dada a relevância que pode ter a avaliação das competências transversais no âmbito da formação de nível superior, este estudo procurou desenvolver um instrumento capaz de mensurar tais competências.

Uma proposta de avaliação das competências transversais coloca em questão quais são as competências que, afinal, deveriam ser avaliadas. $\mathrm{Na}$ literatura existem diversos modelos conceituais de competências transversais (Cabral-Cardoso et al., 2006; Moreno, 2006), e nenhum pode ser considerado necessariamente melhor ou mais completo do que outro. Isso se deve à complexidade do construto competência, que admite diferentes níveis de análise e de abrangência. Em uma revisão de diversas pesquisas que procuraram avaliar competências transversais de trabalho, Cabral-Cardoso et al. (2006) identificaram 41 categorias dessas competências, sendo algumas mais amplas, como "trabalho em grupo", e outras mais específicas de certas áreas de atuação, como "assunção de risco".

Diante da diversidade de definições de competências transversais de trabalho existentes, tomou-se como referência inicial, neste estudo, um modelo descrito por Moreno (2006) aplicável ao contexto do ensino superior. Este modelo especifica sete competências transversais (autonomia, iniciativa, resolução de problemas, trabalho em equipe, organização no trabalho, responsabilidade no trabalho e relações interpessoais) e foi escolhido por ser parcimonioso (sintetiza diversas competências descritas na literatura em sete grupos) e também por ter sido proposto para universitários (embora não tenha sido testado empiricamente). Segundo Moreno, este modelo baseia-se em uma lei de 1999 da região da Catalunha, Espanha, que propôs tais competências transversais como possíveis objetivos de aprendizagem no ensino superior. Essa lei foi uma tentativa de estabelecer um parâmetro para as reorganizações curriculares e pedagógicas decorrentes da Declaração de Bolonha, uma reforma universitária proposta no âmbito da comunidade europeia em 1999, que teve por objetivo criar padrões comuns para o ensino superior europeu, permitindo uma equivalência e reconhecimento dos diplomas expedidos dentro desse sistema. Esta reforma buscou ampliar as possibilidades de integração durante a formação e também de inserção dos egressos no mercado de trabalho europeu, permitindo um trânsito de 
estudantes e profissionais entre diferentes países. Esta tentativa de repensar o processo educativo, aproximando os contextos educacional e laboral, colocou em evidência a necessidade de pensar o desenvolvimento das competências transversais já dentro da formação profissional universitária (Moreno, 2005).

Como indica Moreno (2005; 2006), porém, não há um modelo ou tipologia de competências transversais de trabalho predominante ou estabelecido. De fato, algumas outras competências que não as descritas anteriormente também têm sido mencionadas na literatura. Em função disso, optou-se por incluir neste estudo as competências de comunicação oral, comunicação escrita e raciocínio numérico que são consideradas transversais em várias outras pesquisas (Cabral-Cardoso et al., 2006) e que complementam o modelo proposto por Moreno (2006). Tais competências aparecem em listas de competências consideradas importantes na formação universitária, como o modelo da Liverpool John Moores University, chamado LJMU PLUS (Liverpool John Moores University, 2006).

Cabe notar que não foi localizado na literatura publicada em periódicos científicos nenhum instrumento especificamente desenvolvido para avaliar autopercepções de competências transversais com universitários na forma de escalas ou inventários. Nas pesquisas localizadas, as competências foram avaliadas através de itens únicos. O único estudo que buscou agrupar os itens utilizados em subescalas (através de análise fatorial) foi o de Cabral-Cardoso et al. (2006), mas tal procedimento foi feito a posteriori e de modo exploratório, sem a intenção de construir um instrumento. Os autores identificaram, a partir de conjunto de 36 itens de competências, seis fatores que foram designados de "traços/competências individuais" (agrupando características variadas como autocontrole, iniciativa, motivação, relacionamento interpessoal, tomada de decisão, entre outras), "liderança/negócios" (por exemplo, sensibilidade para os negócios, orientação ao cliente, assunção de risco), "competências cognitivas" (por exemplo, organização, adaptação à mudança, resolução de problemas), "comunicação" (por exemplo, comunicação escrita e oral), "tecnologia de informação e comunicação" (item único) e "numerácia" (item único). É possível que estes resultados, cuja interpretação é ambígua (especialmente no caso do primeiro fator), tenham sido consequência da falta de um modelo teórico inicial que pudesse ter orientado a elaboração dos itens empregados na pesquisa.

Embora não seja possível estabelecer um modelo teórico exaustivo de competências transversais, a construção de um instrumento precisa partir de algum esquema de referência. Assim, como já mencionado anteriormente, para esta pesquisa optou-se por considerar as dimensões de competências propostas por Moreno (2006), acrescidas das dimensões de comunicação oral, comunicação escrita e raciocínio numérico. As definições de cada dimensão utilizadas neste estudo, baseadas em Moreno e no modelo LJMU PLUS (Liverpool John Moores University, 2006), foram as seguintes: 1) Resolução de Problemas (habilidade para enfrentar e dar resposta a uma situação determinada mediante a organização e/ou aplicação de uma estratégia de sequência operativa (identificar, diagnosticar, formular, solucionar e avaliar), definida ou não, para encontrar uma solução; 2) Organização (habilidade para criar as condições adequadas de utilização dos recursos humanos e/ou materiais existentes, para concluir tarefas com o máximo de eficácia e eficiência); 3) Responsabilidade (capacidade de se demonstrar implicado no trabalho; caracteriza-se pelo zelo por um bom funcionamento dos recursos humanos ou materiais relacionados com a tarefa de trabalho); 4) Trabalho em Equipe (habilidade para colaborar de maneira coordenada para a tarefa realizada conjuntamente por uma equipe de pessoas, com o propósito de atingir objetivos comuns); 5) Autonomia (capacidade para realizar uma tarefa de forma independente, sendo capaz de decidir sobre sua execução e de executá-la do início ao fim sem necessidade de receber nenhuma ajuda externa ou apoio); 6) Relação interpessoal (habilidade para comunicar-se com outras pessoas com um trato adequado, com atenção e empatia); 7) Criatividade e flexibilidade (capacidade de ajustar-se a novas circunstâncias e situações, sendo capaz de mudar o modo de agir e pensar com o propósito de melhorar o resultado do trabalho); 8) Comunicação Oral (capacidade de expressar-se eficazmente em forma verbal para um grupo de pessoas e também em situações de relacionamento individual); 9) Comunicação Escrita (habilidade para expressar ideias eficazmente e transmitir informação apropriada através da palavra escrita ou outro tipo de mídia); 10) Raciocínio Numérico (habilidade de realizar operações aritméticas básicas e de lidar com números de um modo geral, interpretando corretamente dados quantitativos e deles extraindo informações úteis).

Com o intuito de possibilitar o desenvolvimento de estudos sobre o tema das competências transversais de trabalho com universitários, esta pesquisa teve então como objetivo construir um instrumento para avaliar a autopercepção de tais competências nesse tipo de população. Além disso, procurouse obter algumas evidências de validade e fidedignidade para o instrumento em questão. Deve estar claro que o instrumento não se propõe à avaliação das competências enquanto desempenho manifesto, e sim autopercepções sobre o desenvolvimento das mesmas.

\section{Método}

\section{Participantes}

A amostra foi composta por 777 estudantes universitários com idades entre 18 e 33 anos $(M=22,4 ; D P=3,02)$. Destes, $55 \%$ eram mulheres e $45 \%$ homens. Os participantes eram provenientes de duas universidades do estado do Rio Grande do Sul: uma pública, da capital $(81,3 \%)$, e outra privada, do interior do estado (18,7\%), tendo-se coletado dados em 34 cursos diferentes. Os cursos que contaram com maior representação na amostra foram: Letras (12,7\%), Farmácia (12,1\%), Educação Física (8,4\%), Nutrição (6,7\%), Psicologia (5,7\%), Odontologia (5,0\%), Física (4,9\%), Agronomia (4,5\%), Administração (4,4\%) e Engenharia Mecânica (4,3\%). Os demais cursos (31,3\%) tiveram representação individual inferior a 4\% do total. Em relação à etapa (semestre) de seus cursos, os estudantes mostraram-se assim distribuídos: $3^{-}$e $4^{-0}$ semestres (40,2\%), $5^{\mathrm{o}}$ e $6^{\mathrm{o}}$ semestres $(26,7 \%), 7^{\mathrm{o}}$ e $8^{\mathrm{o}}$ semestres $(25,5 \%)$ e $9^{\mathrm{o}}$ e $10^{\mathrm{o}}$ semestres (7,6\%). A duração total dos cursos pesquisados era de 8 ou 10 semestres. Em relação ao nível socioeconômico dos 
pais predominou o terceiro grau completo (38,5\% - pais; $42,0 \%$ mães), seguido de segundo grau completo ou terceiro incompleto (35,0\% - pais; $36,7 \%$ - mães) e segundo grau incompleto ou inferior (26,6\% - pais; $21,4 \%$ - mães).

\section{Instrumento}

Para caracterizar e descrever a amostra foi utilizada uma ficha de características sociodemográficas. O outro instrumento empregado foi a Escala de Autopercepção de Competências Transversais de Trabalho (cuja construção foi o foco da pesquisa), em sua versão de 81 itens (após as análises semântica e de juízes).

Para a elaboração dos itens do instrumento foram utilizadas como referência as definições das dez competências transversais descritas na introdução, e também sugestões de itens presentes na literatura. Foram criados, em média, nove itens para cada dimensão, visando contemplar os aspectos contidos em cada atributo (ao todo, a versão inicial contou com 93 itens). Os itens foram elaborados de forma a serem respondidos em uma escala Likert de cinco pontos ( $1=$ Eu tenho esta capacidade quase nada desenvolvida; 2 = Eu tenho esta capacidade pouco desenvolvida; 3 = Eu tenho esta capacidade moderadamente desenvolvida; $4=$ Eu tenho esta capacidade bem desenvolvida; $5=$ Eu tenho esta capacidade muito bem desenvolvida). Após esta etapa, os itens foram submetidos a uma análise semântica junto a oito estudantes universitários, que analisaram a facilidade de compreensão dos itens ou não. Com base nas indicações dadas pelos estudantes, alguns itens sofreram pequenas reformulações na redação, e três itens de difícil compreensão foram eliminados.

O passo seguinte foi a análise dos itens por juízes, que foi realizada por cinco psicólogas que trabalhavam com desenvolvimento de carreira. Itens que não foram avaliados por no mínimo três dos cinco juízes em uma mesma categoria de competência foram eliminados do conjunto. Com as exclusões, restaram 81 itens. Por fim, realizou-se uma aplicação-piloto desta última versão em uma amostra de 109 alunos universitários. Partindo-se da expectativa inicial acerca da composição das escalas, foram realizadas análises de correlação item-restante e de consistência interna para cada uma das dez dimensões previstas. Os resultados destas análises não sugeriram a necessidade de reformulação ou exclusão de nenhum item.

\section{Procedimentos}

Os dados foram coletados em duas universidades, uma pública e outra privada. Os cursos foram selecionados buscando representar diferentes áreas de conhecimento. Inicialmente fezse o contato com as coordenações dos cursos, que indicaram os professores de algumas turmas nas quais possivelmente a coleta dos dados poderia ser realizada. A aplicação dos instrumentos ocorreu conforme conveniência e disponibilidade dos professores para ceder um espaço em sala de aula para a coleta. O tempo médio de aplicação dos instrumentos foi de aproximadamente 30 minutos. Antes da aplicação dos instrumentos, os estudantes foram esclarecidos sobre os objetivos e procedimentos do estudo, assinando um termo de consentimento de participação na pesquisa. Previamente à coleta de dados, o projeto foi aprovado pelo Comitê de Ética em Pesquisa do Instituto de Psicologia da universidade a que estavam vinculados os pesquisadores.

\section{Resultados}

Os resultados são apresentados em três blocos. Inicialmente, a estrutura dimensional do instrumento foi verificada através de sucessivas análises de componentes principais. Uma vez determinados os itens que compuseram cada escala de competência, foram feitas análises descritivas. Por fim, análises de correlação foram empregadas para examinar as relações entre as diferentes subescalas do instrumento (competências).

\section{Análise da estrutura de componentes do instrumento}

A primeira análise realizada com o conjunto dos 81 itens foi uma análise de componentes principais, com rotação oblíqua. A opção pela rotação oblíqua deveu-se à expectativa (conceitual) de que as competências, embora sejam distintas, apresentem relações entre si. Verificou-se que, para esta análise, havia dados completos relativos a 636 protocolos. Este conjunto de casos foi utilizado em todas as análises subsequentes referentes à estrutura do instrumento. O índice Kaiser-Meyer-Olkin de adequação da amostra obtido foi de 0,95 , e o teste de esfericidade de Bartlett mostrou-se significativo $(p<0,001)$, indicando que os dados eram adequados para a análise de componentes. Esta análise revelou a presença de 15 componentes com autovalores maiores do que um, que explicavam $58,6 \%$ da variância total. Porém, o gráfico de scree sugeriu que o critério do autovalor maior do que um para a extração dos componentes resultaria em uma solução com muitos componentes de pouca relevância em termos de capacidade explicativa e possivelmente de difícil interpretação. De fato, foi o que se verificou quando se analisou a matriz de cargas componenciais para estes 15 componentes, descartando-se esta solução.

A fim de identificar o número de componentes mais adequado para representar o conjunto de itens, foi então realizada uma análise paralela, que sugeriu a presença de oito componentes relevantes. Como este número era inferior ao número de dimensões previstas quando da elaboração do instrumento (que eram 10), optou-se por realizar análises sucessivas, com 10, $9,8,7$ e 6 componentes, buscando-se uma solução que fosse mais facilmente interpretável (mantendo-se os 81 itens). A cada análise a matriz de cargas componenciais (com rotação oblíqua) foi analisada quanto à interpretabilidade geral dos componentes, sendo que a solução de sete componentes foi a que se mostrou mais coerente com as expectativas iniciais. Nesta solução de sete componentes, que explicou $46,4 \%$ da variância total, os itens referentes à resolução de problemas e criatividade tenderam a carregar no mesmo componente, assim como os itens relacionados à organização, responsabilidade e autonomia. Já os itens de relacionamento interpessoal, trabalho em equipe, comunicação escrita, comunicação oral e raciocínio numérico constituíram componentes independentes. Esta foi considerada uma solução teoricamente consistente, pois os "agrupamentos" de itens observados foram coerentes. É importante ressaltar que, nestas análises iniciais, nem todos os itens apresentaram cargas componenciais de acordo com o esperado. Alguns carregaram em componentes não previstos, outros não apresentaram 
cargas satisfatórias (ao menos 0,30 ) em nenhum componente, outros ainda carregaram em mais de um componente. Estes itens "problemáticos", contudo, não chegaram a prejudicar a interpretabilidade global das soluções encontradas nesta primeira rodada de análises, que tiveram por objetivo identificar o melhor número de componentes a ser extraído.

A partir da definição do número de componentes a serem extraídos (sete), foram feitas novas análises buscando eliminar itens cujas cargas componenciais eram baixas ou que indicavam ambiguidade do item em relação aos componentes (carga em mais de um componente). Na primeira retirada foram eliminados os itens que apresentaram cargas componenciais inferiores a 0,30 nos sete componentes (cinco itens). Após nova análise, foram retirados itens que tinham carga superior a $0,30 \mathrm{em}$ mais de um componente (seis itens). Mais uma vez a análise de componentes foi conduzida, e os resultados sugeriram a exclusão de mais itens. Nesta terceira retirada considerou-se a pertinência de conteúdo de cada item em relação aos demais itens que carregaram no componente, bem como a presença de cargas superiores a 0,30 em mais de um componente (foram retirados mais sete itens). Uma nova análise foi feita, a qual ainda indicou um item sem carga superior 0,30 em nenhum componente. Este item foi eliminado, e os 62 itens que permaneceram foram submetidos a mais uma análise de componentes principais.

Os resultados desta última análise mostraram-se satisfatórios. O índice Keiser-Meyer-Olkin obtido foi de 0,94 e o teste de esfericidade de Bartlett teve $p<0,001$. Cada item apresentou carga de pelo menos $0,30 \mathrm{em}$ apenas um dos sete componentes. A fim de verificar se o número de componentes extraídos era apropriado a este conjunto reduzido de 62 itens, foi feita uma inspeção visual do gráfico de scree e uma nova análise paralela. Ambos os procedimentos indicaram que sete componentes era um número adequado de dimensões para este conjunto de dados. A Tabela 1 traz a estrutura de componentes obtida, juntamente com as comunalidades para cada item e o percentual de variância explicado por cada componente. A variância total explicada foi de $49,2 \%$.

Os sete componentes encontrados foram assim denominados (exemplos de itens são apresentados entre parênteses): 1) criatividade e resolução de problemas ("Combinar ideias e informações de maneira original", "Analisar vantagens e desvantagens em possíveis soluções de um problema"); 2) organização e responsabilidade ("Organizar-me frente às tarefas que preciso realizar", "Dedicar-me nas minhas tarefas a fim de obter bons resultados"); 3) raciocínio numérico ("Lidar com números de uma maneira precisa e com confiança", "Compreender dados em gráficos e tabelas"); 4) relacionamento interpessoal ("Tratar os outros com cordialidade", "Demonstrar empatia e atenção quando estou falando com outras pessoas"); 5) comunicação escrita ("Escrever de forma que seja compreendido pelos leitores", "Apresentar um texto na formatação adequada aos objetivos propostos"); 6) comunicação oral ("Comunicarse claramente com outras pessoas através da fala", "Escutar e expressar minhas ideias em situações grupais"); e 7) trabalho em equipe ("Dividir tarefas com outras pessoas a fim de chegar a um objetivo comum", "Trabalhar em equipe").

\section{Composição das escalas - análises descritivas e de fidedignidade}

Uma vez identificados os itens mais relevantes em cada componente (como consta na Tabela 1), estes foram utilizados para compor escalas independentes. A Tabela 2 traz dados relativos a cada uma dessas escalas. As médias foram calculadas considerando o intervalo de respostas dos itens (1 até 5). Para o cômputo das médias admitiu-se a existência de dados faltantes nas respostas dos participantes, tendo-se substituído pela média as informações omissas.

Como se pode observar na Tabela 2, as correlações itemrestante, em todas as sete escalas, variaram entre 0,36 e 0,71 , valores que podem ser considerados adequados. Também os alphas de Cronbach observados neste estudo foram satisfatórios, situando-se entre 0,74 e 0,91 . As respostas dos participantes nos itens tenderam a localizar-se na metade superior da escala de respostas, uma vez que as médias situaram-se acima do ponto médio da escala (que é 3).

\section{Correlações entre as escalas}

A Tabela 3 apresenta as correlações (Pearson) entre as escalas de competências transversais de trabalho identificadas no instrumento. Como se nota na Tabela 3 , as correlações entre as escalas situaram-se entre 0,19 e 0,63 . Segundo os critérios de Cohen (1992), a escala de raciocínio numérico apresentou correlações fracas (até próximo de 0,30 ) com as demais escalas, enquanto a força das correlações entre as outras escalas variaram de moderadas (entre 0,30 e 0,50 ) a fortes (acima de 0,50 ).

\section{Discussão}

O objetivo central desta pesquisa foi construir um instrumento capaz de avaliar a autopercepção de competências transversais de trabalho em estudantes universitários. Inicialmente, foi proposto um modelo com dez dimensões distintas entre si. Contudo, a análise de componentes indicou um novo arranjo de competências, considerando o conjunto de itens utilizado. Algumas dimensões, antes separadas, tenderam a colapsar e assim se obteve uma nova estrutura composta por sete componentes. Dessa forma, algumas dimensões de competências se uniram formando um único componente.

O primeiro componente agrupou resolução de problemas e criatividade, o que faz sentido quando se considera que a criatividade é muitas vezes um elemento necessário à resolução de problemas. Já o segundo componente, denominado de organização e responsabilidade, reuniu principalmente itens relacionados à organização e responsabilidade, além de alguns de autonomia. De fato, quando se pensa o uso efetivo dessas habilidades em situações concretas que demandam ação por parte do sujeito, é possível que esses três elementos não se manifestem isoladamente. Por outro lado, os itens de relacionamento interpessoal, trabalho em equipe, comunicação escrita, comunicação oral e raciocínio numérico constituíram componentes independentes, conforme esperado. Esse resultado indica que tais competências, embora possam manter relações conceituais entre si, podem ser consideradas empiricamente 
Tabela 1

Estrutura de componentes do instrumento (cargas componenciais)

\begin{tabular}{|c|c|c|c|c|c|c|c|c|c|c|c|}
\hline \multicolumn{3}{|c|}{ Componente 1} & \multicolumn{3}{|c|}{ Componente 2} & \multicolumn{3}{|c|}{ Componente 3} & \multicolumn{3}{|c|}{ Componente 4} \\
\hline item & carga & $h^{2}$ & item & carga & $h^{2}$ & item & carga & $h^{2}$ & item & carga & $h^{2}$ \\
\hline 37 & 0,73 & 0,57 & 48 & $-0,75$ & 0,59 & 55 & 0,85 & 0,68 & 17 & 0,69 & 0,50 \\
\hline 46 & 0,71 & 0,58 & 44 & $-0,71$ & 0,55 & 80 & 0,85 & 0,67 & 69 & 0,64 & 0,48 \\
\hline 63 & 0,65 & 0,46 & 53 & $-0,71$ & 0,55 & 30 & 0,81 & 0,67 & 7 & 0,63 & 0,47 \\
\hline 38 & 0,57 & 0,45 & 24 & $-0,70$ & 0,55 & 3 & 0,73 & 0,55 & 77 & 0,55 & 0,49 \\
\hline 74 & 0,51 & 0,50 & 52 & $-0,69$ & 0,56 & 41 & 0,73 & 0,60 & 49 & 0,54 & 0,35 \\
\hline 47 & 0,47 & 0,50 & 70 & $-0,64$ & 0,39 & & & & 32 & 0,52 & 0,44 \\
\hline 19 & 0,45 & 0,46 & 59 & $-0,61$ & 0,54 & & & & 16 & 0,49 & 0,39 \\
\hline 71 & 0,37 & 0,32 & 31 & $-0,60$ & 0,46 & & & & 11 & 0,48 & 0,35 \\
\hline 62 & 0,36 & 0,50 & 51 & $-0,60$ & 0,54 & & & & & & \\
\hline 23 & 0,35 & 0,43 & 67 & $-0,59$ & 0,38 & & & & & & \\
\hline \multirow[t]{8}{*}{15} & 0,34 & 0,35 & 9 & $-0,59$ & 0,40 & & & & & & \\
\hline & & & 39 & $-0,53$ & 0,40 & & & & & & \\
\hline & & & 25 & $-0,52$ & 0,41 & & & & & & \\
\hline & & & 75 & $-0,51$ & 0,40 & & & & & & \\
\hline & & & 22 & $-0,41$ & 0,33 & & & & & & \\
\hline & & & 10 & $-0,34$ & 0,32 & & & & & & \\
\hline & & & 54 & $-0,34$ & 0,35 & & & & & & \\
\hline & & & 35 & $-0,31$ & 0,43 & & & & & & \\
\hline \multicolumn{3}{|c|}{ Componente 5} & \multicolumn{3}{|c|}{ Componente 6} & \multicolumn{3}{|c|}{ Componente 7} & & & \\
\hline item & carga & $h^{2}$ & item & carga & $h^{2}$ & item & carga & $h^{2}$ & & & \\
\hline 66 & 0,79 & 0,66 & 29 & $-0,76$ & 0,66 & 4 & 0,71 & 0,58 & & & \\
\hline 45 & 0,79 & 0,67 & 76 & $-0,70$ & 0,61 & 40 & 0,66 & 0,60 & & & \\
\hline 14 & 0,74 & 0,53 & 18 & $-0,67$ & 0,60 & 12 & 0,50 & 0,39 & & & \\
\hline 81 & 0,74 & 0,65 & 34 & $-0,63$ & 0,54 & 8 & 0,46 & 0,39 & & & \\
\hline 42 & 0,70 & 0,59 & 68 & $-0,54$ & 0,49 & 43 & 0,45 & 0,37 & & & \\
\hline \multirow[t]{3}{*}{61} & 0,70 & 0,62 & 73 & $-0,51$ & 0,38 & 20 & 0,41 & 0,41 & & & \\
\hline & & & 1 & $-0,45$ & 0,36 & & & & & & \\
\hline & & & 78 & $-0,39$ & 0,44 & & & & & & \\
\hline
\end{tabular}

Tabela 2

Médias, desvios-padrão e alpha de Cronbach das escalas

\begin{tabular}{lccccc}
\hline Escala & $\begin{array}{c}\mathrm{N}^{\mathbf{0}} \text { de } \\
\text { itens }\end{array}$ & Média & $D P$ & $\begin{array}{c}\text { Correlações } \\
\text { item-restante }\end{array}$ & $\begin{array}{c}\text { Alpha de } \\
\text { Cronbach }\end{array}$ \\
\hline Criatividade e resolução de problemas & 11 & 3,65 & 0,60 & $0,42-0,64$ & 0,87 \\
Organização e responsabilidade & 18 & 3,82 & 0,60 & $0,46-0,69$ & 0,91 \\
Raciocínio numérico & 5 & 3,68 & 0,87 & $0,60-0,71$ & 0,85 \\
Relacionamento interpessoal & 8 & 4,12 & 0,57 & $0,45-0,56$ & 0,80 \\
Comunicação escrita & 6 & 3,85 & 0,73 & $0,58-0,70$ & 0,86 \\
Comunicação oral & 8 & 3,64 & 0,67 & $0,46-0,70$ & 0,85 \\
Trabalho em equipe & 6 & 3,67 & 0,63 & $0,36-0,59$ & 0,74 \\
\hline
\end{tabular}

Tabela 3

Correlações entre as escalas

\begin{tabular}{lllllll}
\hline Escala & 1 & 2 & 3 & 4 & 5 & 6 \\
\hline 1. Criatividade e resolução de problemas & - & & & & & \\
2. Organização e responsabilidade & 0,60 & - & & & & \\
3. Raciocínio numérico & 0,33 & 0,29 & - & & & \\
4. Relacionamento interpessoal & 0,46 & 0,43 & 0,20 & - & & \\
5. Comunicação escrita & 0,46 & 0,42 & 0,19 & 0,44 & - & \\
6. Comunicação oral & 0,63 & 0,52 & 0,21 & 0,51 & 0,51 & - \\
7. Trabalho em equipe & 0,52 & 0,49 & 0,26 & 0,58 & 0,41 & 0,52 \\
\hline
\end{tabular}

Nota: em todos os casos $p<0,001$ ( $n$ entre 771 e 773) 
distintas.

O agrupamento observado de algumas competências demanda uma reflexão sobre o modo como se definem e operacionalizam as competências transversais. Como indicado na introdução, não há consenso na literatura sobre qual conjunto de competências é o mais importante de ser considerado, bem como sobre a definição das próprias competências (Cabral-Cardoso et al., 2006; Moreno, 2006). Embora, de um modo geral, as definições possam até apresentar uma razoável distinção e clareza conceitual na literatura, elas tendem a ser pouco específicas, dificultando compreender como as competências transversais se expressam de fato em situações concretas (Lucas et al., 2004). Neste estudo, as definições utilizadas (baseadas em Moreno, 2006) seguiram a tendência de serem abrangentes, não havendo uma preocupação inicial em estabelecer limites conceituais nítidos para as competências. Todavia, a operacionalização das mesmas em itens descritores foi submetida à avaliação de juízes que, minimamente, indicaram a adequação dos itens às dimensões previstas.

Apesar desse cuidado metodológico, contudo, os resultados sugerem que algumas competências parecem estar muito relacionadas, ao ponto de não se distinguirem empiricamente, possivelmente devido à existência de uma "base comum" a elas. Nesse sentido, um ponto que precisa ser considerado em pesquisas futuras é a provável relação existente entre alguns tipos de competências e a personalidade. Por exemplo, o agrupamento dos descritores relacionados com organização, responsabilidade e autonomia faz pensar na influência subjacente de um traço de personalidade usualmente chamado de realização ou conscienciosidade, do modelo dos Cinco Grandes Fatores (Digman, 1990). A junção de resolução de problemas e criatividade, por sua vez, sugere a presença de características do traço de abertura à experiência. Essa aproximação da definição de certas competências com definições de personalidade requer um exame mais detido no futuro, pois se as competências forem percebidas como atributos intrínsecos às pessoas, como sugere o estudo de Lucas et al. (2004), então pode tornar-se difícil sensibilizar os indivíduos para o desenvolvimento destas competências.

Apesar do problema conceitual não ter sido contornado nesta pesquisa, os resultados obtidos contemplam o objetivo que foi construir um instrumento para avaliar a autopercepção de competências transversais em universitários. Embora a análise de componentes principais realizada com os itens do instrumento tenha revelado uma estrutura diferente da prevista inicialmente, a solução obtida foi clara em termos das cargas dos itens nos componentes, além de ser coerente e interpretável. Este resultado pode ser considerado uma evidência de validade parcial do modelo de competências proposto, na medida em que nem todas as dimensões emergiram empiricamente da análise.

No que diz respeito às evidências de fidedignidade do instrumento, os valores observados nos índices de consistência interna alpha de Cronbach foram adequados, sendo seis deles superiores a 0,80. Apenas a dimensão Trabalho em Equipe apresentou um índice um pouco inferior $(0,74)$. De todo modo, trata-se de um valor ainda adequado, especialmente quando se considera o pequeno número de itens dessa escala. Tomados em conjunto, os resultados da análise de componentes principais e das análises de fidedignidade das escalas mostram que o instrumento é capaz de avaliar a autopercepção de diferentes competências transversais de trabalho em universitários de uma forma consistente.

Os escores das escalas de competências mostraram-se ainda correlacionados, mas não ao ponto de sugerir uma sobreposição das medidas. Esse resultado revela que as competências avaliadas são inter-relacionadas, mas conservam suas distinções. A única competência que apresentou correlação mais baixa com todas as outras foi a de raciocínio numérico. Este dado indica que esta competência refere-se a uma habilidade mais específica e menos associada às demais. As outras competências, porém, apresentaram correlações médias e fortes, sugerindo que, quando uma é percebida como bem desenvolvida, as demais também tendem a ser percebidas como bem desenvolvidas.

Como se verifica nos resultados obtidos, os universitários avaliaram-se com médias acima do ponto médio das escalas, ou seja, perceberam-se com níveis elevados em todas as sete competências (entre "moderadamente desenvolvidas" e "bem desenvolvidas"). Um ponto importante a ser lembrado é que o instrumento procura avaliar a autopercepção das competências, e não as competências em si mesmas (desempenho). Assim, pode ser que os escores estejam refletindo uma autoavaliação baseada não em desempenho real, mas em expectativas de desempenho. É possível que, quanto mais experiência o indivíduo tenha, mais realistas se tornem as suas autoavaliações. Assim, as avaliações bastante positivas feitas pelos estudantes nesta pesquisa talvez sejam resultado de uma percepção superestimada das próprias competências, uma vez que possivelmente os estudantes não tiveram experiências suficientes nas quais essas habilidades tenham sido exigidas ou colocadas à prova ao ponto de eles perceberem a necessidade de um maior desenvolvimento nessas habilidades. Outro fator que pode gerar autoavaliações superestimadas é a falta de hábito de pensar o próprio comportamento em termos de competências (efeito observado em Lucas et al., 2004), levando o indivíduo a produzir respostas mais socialmente desejáveis.

Portanto, as médias elevadas obtidas nas escalas devem ser interpretadas com cautela. Elas podem significar tanto uma autoavaliação ingênua ou otimista das potencialidades quanto uma avaliação mais realista, dependendo do tipo de experiências vivenciadas pelos estudantes. Este resultado de difícil interpretação sinaliza a necessidade de novos estudos que busquem especificar quais os critérios utilizados pelos estudantes ao julgarem suas competências.

Enfim, o instrumento final obtido deve ser interpretado apenas como uma possível maneira de sistematizar e avaliar o domínio das competências transversais de trabalho em universitários. Nem poderia ser diferente, na medida em que o campo conceitual das competências é bastante diversificado, com pouca convergência quanto às quais competências são tidas como mais importantes e também quanto à própria definição das mesmas (Lucas et al., 2004; Moreno, 2006). Apesar disso, acredita-se que o instrumento tem o potencial de dar visibilidade ao tema das competências transversais no ensino superior e estimular a pesquisa sobre o assunto. Como apontam Lucas et al. 
(2004), se de fato pretende-se que o ensino superior tenha como objetivo o desenvolvimento de competências outras que não apenas as técnicas, então é necessário construir um vocabulário que ajude a tornar explícitas as competências transversais. À medida que as competências forem sendo nomeadas e percebidas, então se pode discutir como elas podem ser desenvolvidas e como se relacionam ao processo de formação. Isso tem implicações tanto para os alunos quanto para as instituições. Quando param para refletir sobre o seu processo de formação e as competências que necessitam ou desejam desenvolver, os alunos podem buscar de forma mais ativa o seu autodesenvolvimento, aproveitando melhor as oportunidades oferecidas pelas instituições. Por outro lado, as instituições, ao terem como objetivo o desenvolvimento dessas competências, podem adotar estratégias pedagógicas mais explicitamente voltadas a esse objetivo.

Espera-se que o instrumento construído possa servir como uma ferramenta que estimule novos estudos sobre o tema em universitários. Além disso, ele pode ser útil também como um recurso para fomentar a reflexão sobre o tema das competências transversais com os próprios estudantes, servindo como um ponto de partida para uma exploração qualitativa das experiências de formação relacionadas às competências. Apenas avançando no conhecimento acerca dos processos de formação que se dão no ensino superior será possível saber se esta formação está sendo efetiva, no sentido de capacitar os indivíduos a aprenderem a aprender e a aplicar seus conhecimentos no cotidiano de um modo eficiente e útil para a sociedade e para si mesmos.

\section{Referências}

Alpay, E., \& Walsh, E. (2008). A skills perception inventory for evaluating postgraduate transferable skills development. Assessment \& Evaluation in Higher Education, 33(6), 581-598.

Boterf, L. G. (2003). Desenvolvendo a competência dos profissionais. Porto Alegre: Artmed.

Burke, V., Jones, I., \& Doherty, M. (2005). Analysing student perceptions of transferable skills via undergraduate degree programmes. Active Learning in Higher Education, 6(2), 132-144.

Cabral-Cardoso, C., Estêvão, C. V., \& Silva, P. (2006). Competências transversais dos diplomados do ensino superior: perspectiva dos empregadores e dos diplomados. Guimarães: TecMinho.

Campos, K., Vieira, V., de Camargo, A., Scheguschevski, A., Tavares, F., Piovezan, N., \& Alkschbirs, S. (2008). Empregabilidade e competências: uma análise de universitários sob a ótica de gestores de recursos humanos. Revista Psicologia: Organizações e Trabalho, 8(2), 159-183.

Cohen, J. (1992). A power primer. Psychological Bulletin, 112(1), 155-159.

Cox, S., \&King, D. (2006). Skill sets: an approach to embed employability in course design. Education + Training, 48(4), 262-274.

Digman, J. M. (1990). Personality structure: emergence of the five-factor model. Annual Review of Psychology, 41, 417-440.

Drummond, I., Nixon, I., \& Wiltshire, J. (1998). Personal transferable skills in higher education: the problem of implementing good practice. Quality Assurance in Education, 6(1), 19-27.

Frame, I., \& Canter, M. (2001). A menu of graduate skills: the specification of degree level skills for construction and surveying students. Recuperado de http://rics-foundation.org.

Liverpool John Moores University (2006). LJMU Plus. Recuperado de http:// www.ljmu.ac.uk/MKG_Global_Docs/LJMUPlusConsultation.pdf.

Lucas, U., Cox, P., Croudace, C., \& Milford, P. (2004). 'Who writes this stuff?': student's perceptions of their skills development. Teaching in Higher Education, 9, 55-68.

Moreno, M. L. R. (2005). Las demandas sociales y el mundo laboral ante la integración europea de conocimiento universitario. Cuadernos de Integración Europea, 2, 54-68.

Moreno, M. L. R. (2006). Evaluación, balance y formación de competencias laborales transversales: propuestas para mejorar la calidad en la formación profesional y en el mundo del trabajo. Laertes Educación: Barcelona.

Nabi, G. R., \& Bagley, D. (1999). Graduates' perceptions of transferable personal skills and future career preparation in the UK. Education + Training, 41(4), 184-193.

Whittle, S. R., \& Eaton, D. G. M. (2001). Attitudes towards transferable skills in medical undergraduates. Medical Education, 35, 148-153.

Zabalta, M. A. (2004). O ensino universitário: seus cenários e seus protagonistas. Porto Alegre: ArtMed.

Zekeri, A. A. (2004).College curriculum competencies and skills former students found essential to their careers. College Student Journal, 38(3), 412-422.

Bárbara Maria Barbosa Silva, mestre em Psicologia pela Universidade Federal do Rio Grande do Sul, é coordenadora do Curso de Psicologia da Faculdade Integrada de Santa Maria. Endereço: Rua Marechal Floriano Peixoto, n¹139/apto 111 - Centro. Santa Maria - RS. CEP: 97015-371. Telefone (055) 33042994. Fone/Fax: (055) 30259725. E-mail: babi_mbs@yahoo.com.br

Marco Antônio Pereira Teixeira, doutor em Psicologia pela Universidade Federal do Rio Grande do Sul, é professor no Instituto de Psicologia na Universidade Federal do Rio Grande do Sul. E-mail: mapteixeira@ yahoo.com.br 